\title{
Study on chemotaxis and chemokinesis of bone marrow-derived mesenchymal stem cells in hydrogel-based 3D microfluidic devices
}

\author{
Dayoung Yoon ${ }^{1,2}$, Hyerim Kim³ ${ }^{3}$ Eojin Lee ${ }^{1}$, Min Hee Park' ${ }^{1}$ Seok Chung ${ }^{4}$, Hojeong Jeon ${ }^{1}$, Cheol-Hee Ahn² \\ and Kangwon Lee Le, $^{3 *}$
}

\begin{abstract}
Background: Controlling the fate of mesenchymal stems cells (MSCs) including proliferation, migration and differentiation has recently been studied by many researchers in the tissue engineering field. Especially, recruitment of stem cells to injury sites is the first and crucial step in tissue regeneration. Although significant progress has been made in the chemotactic migration of MSCS, MSC migration in three dimensional environments remains largely unknown. We developed a 3D hydrogel-based microfluidic-device to study the migration behavior of human MSCs in the presence of stromal-cell derived factor-1a (SDF-1a), interleukin 8 (IL-8) and Substance P (SP) which have been utilized as chemoattractant candidates of human mesenchymal stem cells (hMSCs).

Results: We systematically investigated the chemotactic migration behaviors of hMSCS and their responses to SDF-1a, IL-8, and SP. SDF-1a was shown to be the most fascinating chemoattractant candidate among those factors at a certain time point. We also found that each chemokine showed different chemoattractant abilities according to their concentration. In the case of SP, this factor showed chemokinesis not chemotaxis. Especially at a $7-8 \times 10^{-8} \mathrm{M}$ concentration range, the chemokinesis ability driven by SP was further increased. The data suggest that some factors at the optimal concentration exhibit chemokinesis or chemotaxis in a 3D hydrogel-based microfluidic device.
\end{abstract}

Conclusion: In this study on chemotaxis and chemokinesis of hMSCs, the system parameters such as chemokine concentration, system stability, and 2D or 3D microenvironment are critically important to obtain meaningful results.

Keywords: Chemotaxis, Mesenchymal stem cells, Chemokinesis, Microfluidic device

\section{Background}

Chemotactic behavior is a characteristic of various cell types engaging in biological processes such as inflammation, wound repair, organ development, neurite outgrowth, and tumor invasion [1]. A chemoattractant is defined as a chemical agent that induces cell migration toward itself. This agent includes members of the growth factors, cytokines and chemokines [2]. Chemotaxis in cells is the movement of cells toward or away

\footnotetext{
*Correspondence: chahn@@snu.ac.kr; kangwonlee@snu.ac.kr

${ }^{2}$ Research Institute of Advanced Materials (RIAM), Department of Materials Science and Engineering, Seoul National University, Seoul, Republic of Korea ${ }^{3}$ Program in Nanoscience and Technology, Graduate School of Convergence Science and Technology, Seoul National University, Seoul, Republic of Korea Full list of author information is available at the end of the article
}

from a chemical reagent. Attracted cells exhibit positive chemotaxis while repelled cells exhibit negative chemotaxis. While chemotaxis is a directional behavior, chemokinesis is the random movement of cells. Both endogenous and exogenous substances act as chemoattractants. Therefore, the harmony between endogenous stem cell recruitment and exogenous stem cell induction is one of the most critical issues for effective regenerative therapies in tissue engineering. Many researchers in the tissue engineering field have studied many kinds of chemokines or growth factors to recruit mesenchymal stems cells (MSCs) endogenously. MSCs have closely been involved in the process of healing, and their recruitment to the target area is crucial to enhance their 
therapeutic effect in the patients. The ability of MSCs to produce juxtacrine or paracrine factors is very important to induce regeneration from the endogenous stem cells. Studies have been done previously on some cytokines that affect the migration of MSCs to injury sites [3, 4]. There are some important cues that should be controlled such as the stemness of the MSCs, culture conditions, and delivery method to induce MSC migration [5]. Some chemokines and growth factors are known to promote selectively proliferation, migration and differentiation of MSCs [6,7]. For instance, stromal cell-derived factor-1 $\alpha$ (SDF-1 $\alpha)$ mediates cell migration by binding with CXC chemokine receptor-4 (CXCR4) at the site of injury [8-10]. However, most results previously have reported limitations because those are based on a two dimensional (2D) culture. It is well known that cells cultured using traditional 2D tissue culture methods are morphologically different from cells in humans or animals.

Our body has 3 dimensional (3D) structures. The cells compromising each organ interact with other cells or circumstances; thus, microenvironments affect cells significantly. 2D cell cultures are unable to perfectly mimic real cell microenvironments and cannot effectively study cell-cell and cell-extracellular matrix (ECM) interactions. In reality, all cells and tissues in vivo or in clinical condition are placed in 3D microenvironments, and some data from in vivo and clinical research done in 3D conditions show discrepancies with the data obtained from 2D in vitro conditions. Signals in $3 \mathrm{D}$ environments have a key role in cell differentiation, proliferation and migration of cells. A study on a 3D microenvironment is considered similar to the in vivo environment rather than a $2 \mathrm{D}$ culture which lacks, reduces or compromises important signaling events $[11,12]$. Due to the limitations of $2 \mathrm{D}$ cell culture, 3D cell studies using microfluidic devices have greatly received attention enabling one to assay behaviors of stem cells in a controlled microenvironment with spatiotemporal conditions of the factors. There are some benefits such as a low volume of reagents, fast response time, consistent fluid flow on microscale dimensions of the concentration gradient in microfluidics [13, 14]. Therefore, 3D cell culture platforms are useful tools for mimicking the microenvironment of cells and tissues compared to $2 \mathrm{D}$ cell cultures. A number of $3 \mathrm{D}$ microfluidic models have been used to study the migration of neural stem cells (NSCs) [15, 16], leukocytes [17] and tumor cells [18]. Generation of a concentration gradient of cytokines or growth factors inducing single cell responses enable one to characterize the behavior of the cells quantitatively [19].

In this study, we investigated the chemotactic migration of human bone-marrow derived mesenchymal stem cells (hMSCs) with hydrogel-based microfluidic platforms. To control the conditions, we considered the composition of the hydrogels and microfluidic platform systems. Hydrogels are efficient devices to study chemokine gradient effects to quantify hMSC behaviors. The chemotaxis of hMSCs in microfluidic devices follows a stable gradient. Using a 3D microfluidic system, we studied the chemotactic migration behaviors of hMSCs and their responses to chemoattractants in a 3D microenvironment. Three candidates of chemoattractants, SDF- $1 \alpha$, Interleukin-8 (IL-8), and Substance P (SP) were investigated. Furthermore, we determined the optimum concentration for hMSC chemotaxis.

\section{Methods}

\section{Microfluidic device fabrication}

A microfluidic device was prepared as previously described (Singapore model) [16, 20]. The microfluidic device in our study has a 1.3-mm-wide central hydrogel region flanked by two lateral media channels. The device was fabricated with polydimethylsiloxane (PDMS, Sylgard 184; Dow Corning) using soft lithography from patterned SU-8 silicon wafers. Inlet and outlet ports were created with biopsy punches, and a cover glass was bonded to the PDMS after treatment with oxygen plasma for $60 \mathrm{~s}$ to generate 150-um-deep microchannels. The merit of a static condition is that it is possible to investigate up to 6 different conditions including a control condition using a live cell microscope systemically and simultaneously (Carl Zeiss Axio Observer. Z1) (Fig. 1). The change in concentration gradient of the factors was tested with a standard method using $10 \mathrm{kDa}$ FITClabeled dextran. FITC-dextran mixed with the medium was injected into one channel of the device with the same concentration as the growth-factors used.

\section{Cell culture and cell seeding}

Human Bone marrow-derived mesenchymal stem cells (hBM-MSCs) were commercially obtained from Severance Hospital. The hMSCs of passage 6 to 8 were cultured in growth medium prepared with DMEM -low glucose (Gibco) with $10 \%$ (v/v) FBS (Welgene) and $1 \%$ $(\mathrm{v} / \mathrm{v})$ antibiotics. Cells were maintained in culture and used up to the 7 th passage. All cultures were kept in a humidified atmosphere at $37{ }^{\circ} \mathrm{C}$ and $5 \% \mathrm{CO}_{2}$. When needed, cells were trypsinized by standard protocols and washed in PBS. Before seeding, hMSCs at passage 7 were suspended at $2.5 \times 10^{5}$ cells $/ \mathrm{mL}$ in hydrogels. The hydrogels were composed of collagen (collagen type, BD Bioscience) gel $(2 \mathrm{mg} / \mathrm{ml})$ and growth-factor reduced Matrigel (GFR-Matrigel) at a 1:1 ratio (Young's modulus: $9 \mathrm{kPa})$. The gel channel was filled with the cell suspension to complete the seeding. The gelation process occurred within $30 \mathrm{~min}$ in humidity boxes incubated at $37{ }^{\circ} \mathrm{C}$ and $5 \% \mathrm{CO}_{2}$. After gelation, the growth medium 


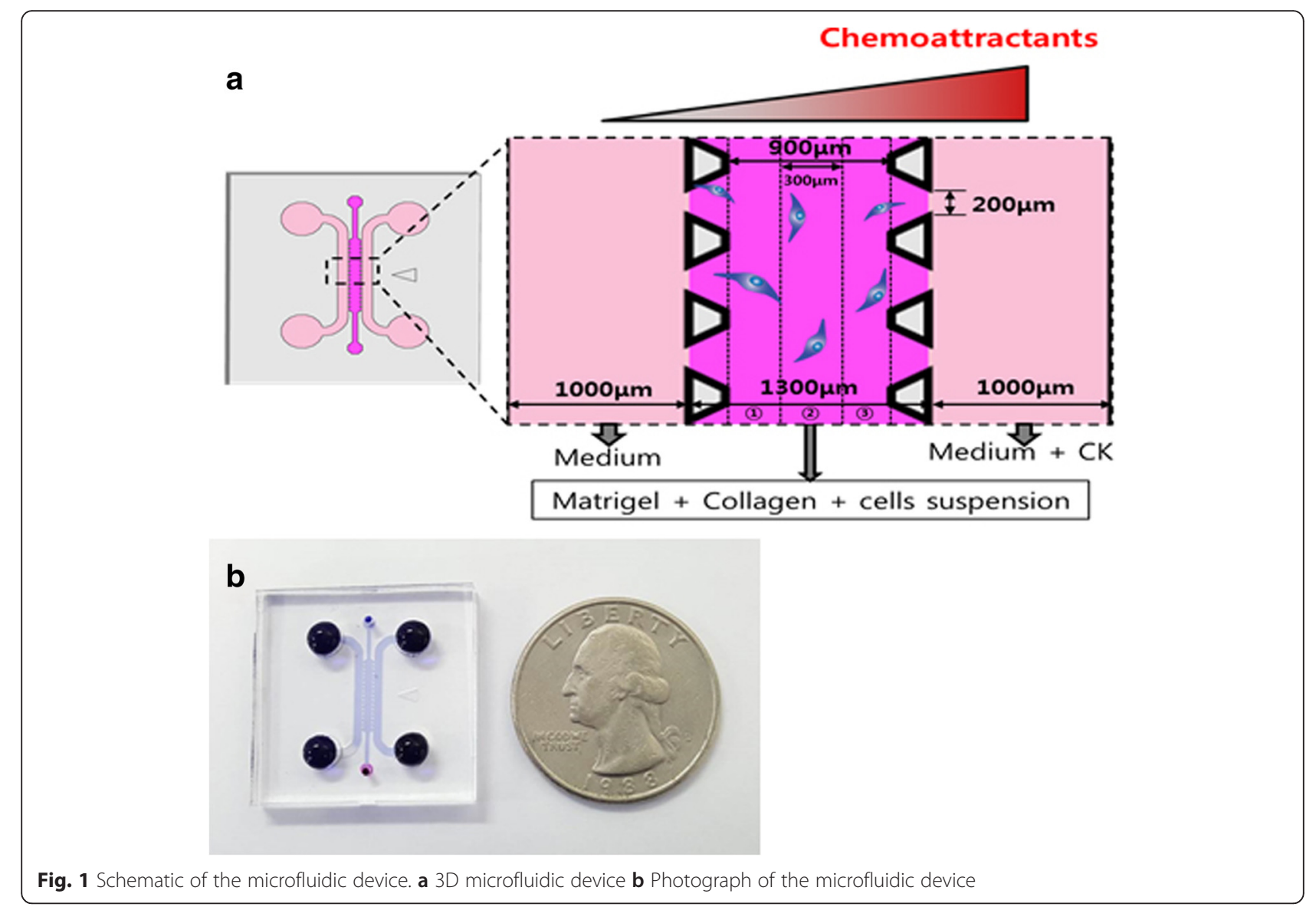

was injected into both side channels, and the gelmicrofluidics were incubated in an incubator for over $24 \mathrm{~h}$.

\section{Chemotaxis and chemokinesis assays}

In the microfluidic device, hMSCs in the hydrogel were cultured overnight. After cell spreading, one of the side channels was treated with the chemokine at the relevant concentrations, and the other side of the channel was filled with blank medium. To find out the optimal concentration, each factor was screened for concentrations ranging from $10^{-6} \mathrm{M}$ to $10^{-10} \mathrm{M}$. The candidates of chemokines used in this study were SDF-1 $\alpha$ (Peprotech), IL-8 (R\&D) and SP (Calbiochem).

\section{Cell tracking and statistical analysis}

Images were taken every $10 \mathrm{~min}$. for $24 \mathrm{~h}$ with a live cell microscope (Carl Zeiss Axio Observer. Z1) incubated at $37{ }^{\circ} \mathrm{C}$ and $5 \% \mathrm{CO}_{2}$. Images from the first $3 \mathrm{~h}$ were not analyzed until the concentration gradient of the channels was stable. In the data analysis, cells in both side sections of the central channel were not counted, and cells in section (2) in Fig. 1a were analyzed. The central channel of the microfluidic device is divided by three

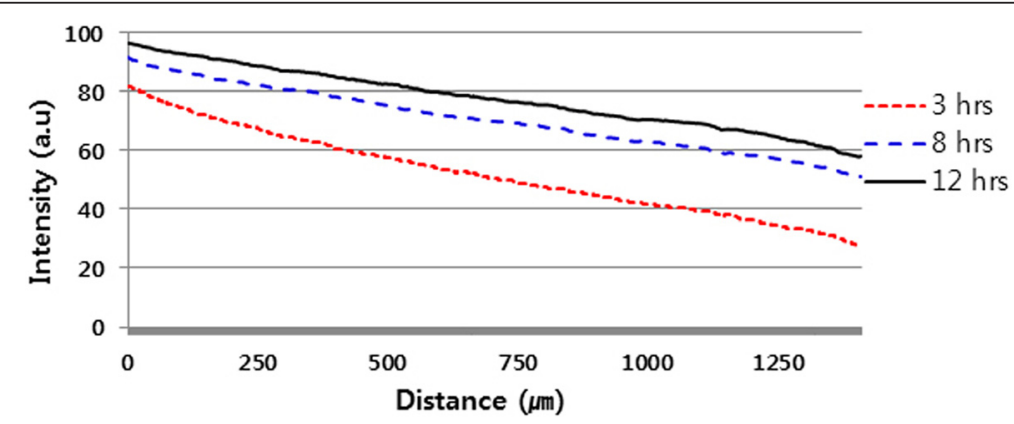

Fig. 2 Results of the diffusion of $10 \mathrm{kDa}$ FITC-dextran solution 


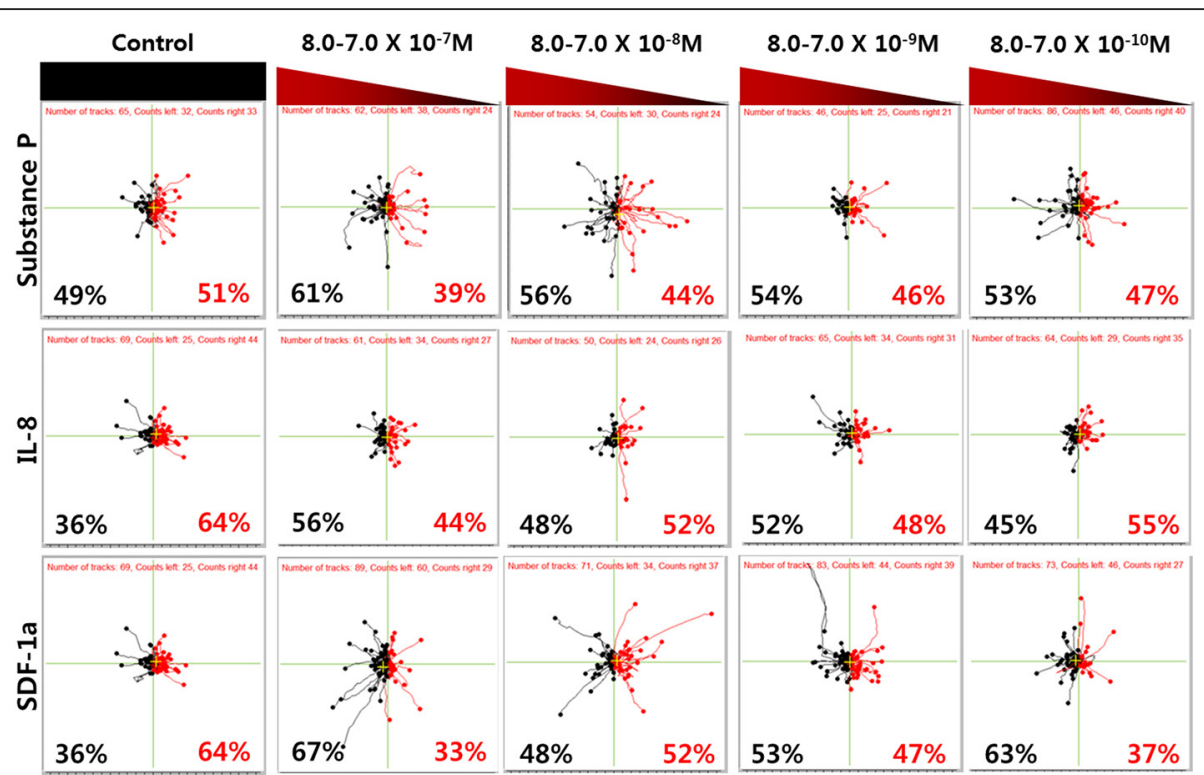

Fig. 3 Tracking diagram of hMSCs according to the various concentration of the underlying substrates. Black pathways indicate migration of cells to the substrate, and red pathways indicate the motion in opposite direction which moves away from the substrate. The numbers in percentage indicate the ratio of migrated cells moving to each direction of tracking cells

sections, and each section has a 300 um length and a 150 um depth shown in Fig. 1a. Human MSC migration was analyzed with MTrackJ, a manual cell-tracking plugin for the NIH ImageJ software. When the cell tracking analysis was done, cells in section (2) were tracked every $20 \mathrm{~min}$ for $10 \mathrm{~h}$. Compass plots of cell tracks and angular histograms were quantified from position data using the Chemotaxis Tool plugin (ibidi, Germany). The variations in directional distance along the $\mathrm{X}$-axis $(\Delta \mathrm{X})$ were analyzed with the Statistical Package for Social Sciences (SPSS).

\section{Results \& discussion}

Microfluidic device identifies chemotactic migration showing stable gradients

To identify chemotactic migration, concentration gradients of chemokines must be maintained stably. We monitored the change in the concentration of the factor

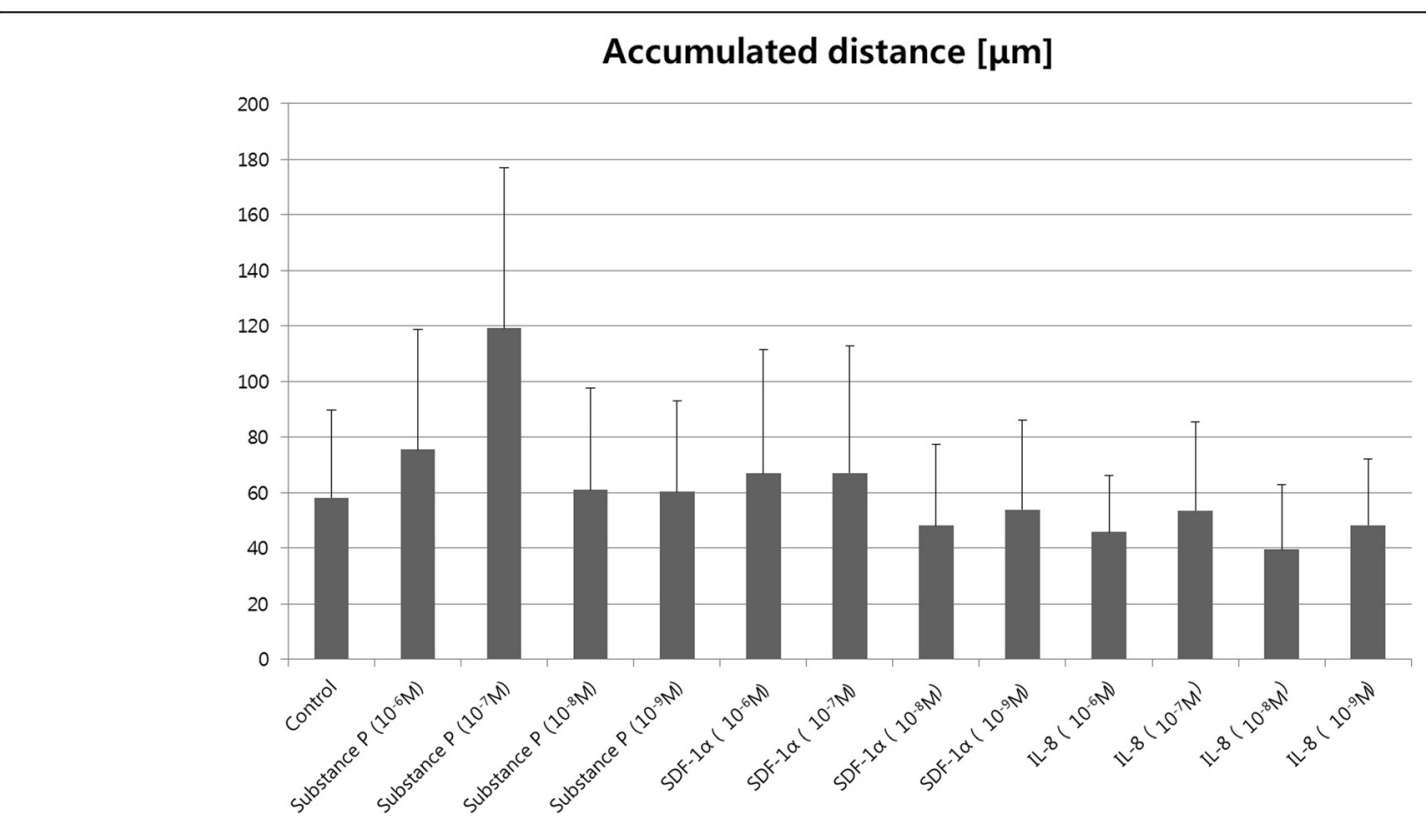

Fig. 4 The accumulated distance of migrated hMSCs. Distance was calculated by the scalar summation of total cell movment over time 
using FITC-dextran. Formation of stable concentration gradients in the microfluidic device was investigated with $10 \mathrm{kDa}$ FITC-dextran $(1 \mu \mathrm{M})$. After the gelation in the central channel, one of the side channels was filled with FITC-dextran solution, and the other one was filled with blank medium. Images and movies were taken every $10 \mathrm{~min}$. for $13 \mathrm{~h}$ with a live cell microscope (Carl Zeiss Axio Observer. Z1). The data analysis was done with MATLAB. The diffusion results with the $10 \mathrm{kDa}$ FITC-dextran solution showed a stable formation of the concentration gradient in Fig. 2. The slopes at 3, 8 and $12 \mathrm{~h}$ were $0.04,0.03$, and $0.03 \mathrm{a} . \mathrm{u} / \mu \mathrm{m}$, respectively. We observed a similar slope over $24 \mathrm{~h}$, which means that our system is suitable for the test during our experimental time range. Throughout the results, stable diffusion in the microfluidic device was determined from 3 to $24 \mathrm{~h}$. We systematically investigated the physical properties of the hydrogels (Matrigel, collagen only, or Matrigel/collagen mixture) to optimize the mechanical property of the hydrogel. This mechanical property of the ECM-mimicking matrix affects cell behaviors including proliferation, migration and differentiation.

\section{Chemokinesis of hMSCs on a chemokine gradient}

To assess chemoattractant migration of hMSCs, we used the 3D microfluidic system which was designed based on the Singapore model originally developed at MIT-KU $[16,20]$. One of the side channels in the microfluidic device was filled with cytokines, and the other side was filled with blank medium without cytokines. The middle channel of the device was filled with the hydrogel containing hMSC cells (Fig. 1).

We investigated cell movement with various concentrations of the three candidates, SP, IL- 8 and SDF- $1 \alpha$, respectively. The control group was tested in the absence of chemokines, and the test groups used gradients of $8.0-7.0 \times 10^{-7}, 8.0-7.0 \times 10^{-8}, 8.0-7.0 \times 10^{-9}$ and 8.0 $7.0 \times 10^{-10} \mathrm{M}$ for the experiment (Fig. 3). SDF- $1 \alpha$ is
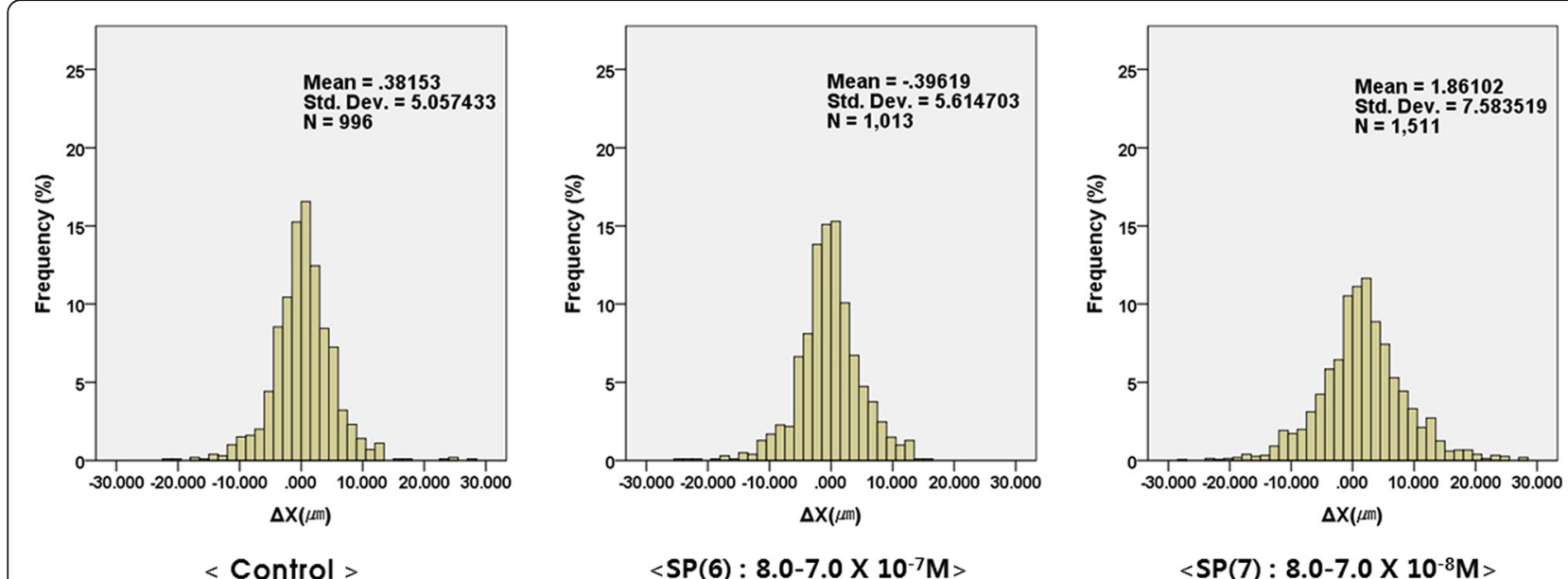

$<\mathrm{SP}(6): 8.0-7.0 \times 10^{-7} \mathrm{M}>$
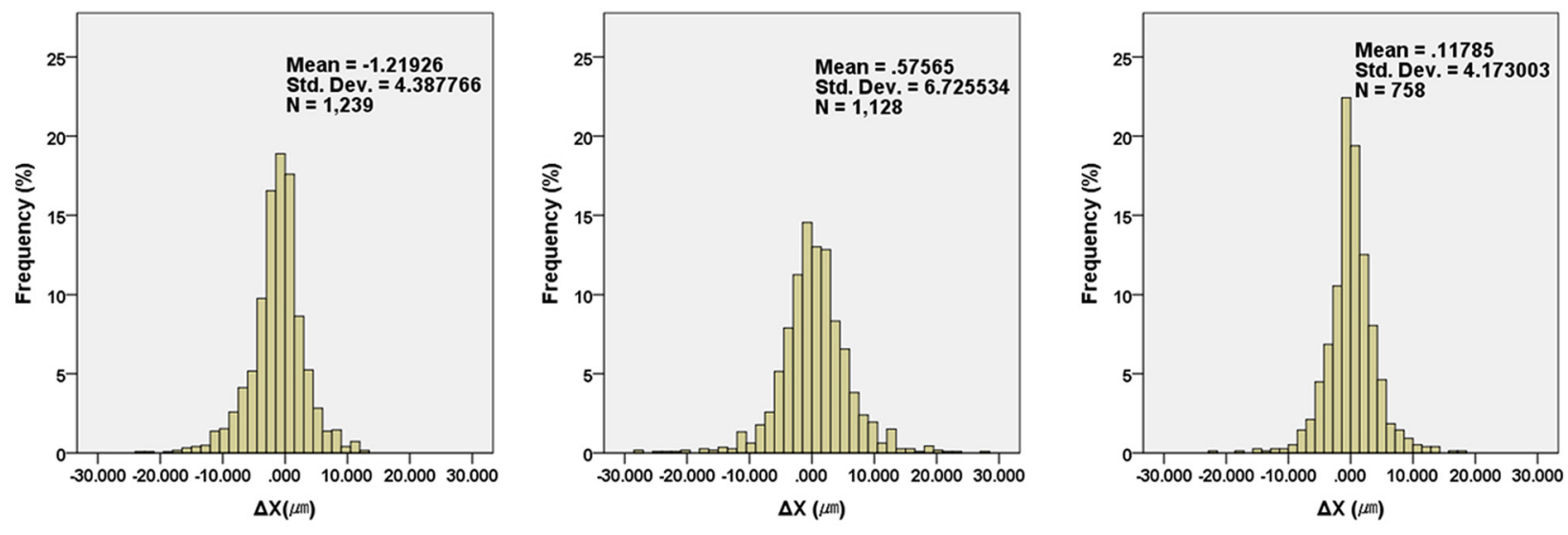

<SDF-1a(6): 8.0-7.0 $\times 10^{-7} \mathrm{M}>$

$<$ SDF-1a(7): 8.0-7.0 $\times 10^{-8} \mathrm{M}>$

$<$ IL-8(6) : 8.0-7.0 X 10-7M>

Fig. $5 \mathrm{X}$-directional distance $(\Delta \mathrm{X})(-30 \mu \mathrm{m}$ to $30 \mu \mathrm{m})$ analyzed by SPSS (Statistical Package for the Social Sciences). Negative signal means the movement toward high concentration, and the positive signal means the movement toward low concentration. The numbers presented on the upper right corner describe mean X-directional distance, standard deviation and total number of data 
known as one of the potential factors inducing the chemotactic migration of mesenchymal stem cells. Compared to the control group without chemokines, the SP group showed movements of cells for concentration ranges at both 8.0-7.0 $\times 10^{-7}$ and 8.0-7.0 $\times 10^{-8} \mathrm{M}$. Similar to the SP group, the SDF-1 $\alpha$ group also showed a meaningful migration of cells for concentration ranges at 8.0-7.0 $\times 10^{-7}$ and 8.0-7.0 $\times 10^{-8} \mathrm{M}$. However, the cells did not move in any certain direction but randomly in arbitrary directions. The distribution of cell migration in Fig. 3 was almost symmetric for both the SP and SDF$1 \alpha$ groups. MSCs migrate in response to an SDF- $1 \alpha$ gradient, and the number of MSCs that migrated in the presence of SDF- $1 \alpha$ was more than double the number of MSCs that migrated in the absence of SDF- $1 \alpha$ which means that our result with SDF- $1 \alpha$ is in agreement with a previous report [21]. In the results with IL-8, we did not observe any noticeable migration over the concentration ranges tested. It seems that the effect of IL-8 inducing the directional migration of hMSCs is less than the other two chemokines. This means that the hMSCs did not show any tendency of cell chemotaxis or chemokinesis compared to the control group with IL-8 in 3D conditions. A study reported previously that IL-8 secreted from kidney cancer cells induced the migration of MSCs significantly to the kidney cancer cells [22]. This discrepancy in the migration behaviors might be due to the difference in experimental conditions between the $2 \mathrm{D}$ in vitro (e.g., Transwell test) and the $3 \mathrm{D}$ study we conducted. The Transwell test commonly used in chemotaxis studies does not respond or mimic the 3D microenvironment of cells, and the data from the 2D Transwell test may give different results from the data obtained with the 3D hydrogel matrix.

SP has also been regarded as a potential factor for the chemotactic migration of MSCs. It was reported previously that SP induces transmigration and the proliferation of bone marrow stromal cells (BMSCs) [23]. We further investigated the cumulative distance of the hMSCs which indicates the total distance of cell movement (Fig. 4). The accumulated distances were obtained from the start point of the cell migration to the endpoint of each leading edge [24]. As shown in Fig. 4, hMSCs in the $10^{-7} \mathrm{M} \mathrm{SP}$ gradient $\left(8.0-7.0 \times 10^{-8} \mathrm{M}\right)$ had a higher value for cumulative distance compared to the control group. We confirmed that the activity of the migrated cells is in agreement with the result in Fig. 3 for SP (8.0$\left.7.0 \times 10^{-8} \mathrm{M}\right)$. We believe that the cumulative distance in the hMSC migration test is closely related with the dynamic behavior of cells, and it means that the cells have better motility based on the higher value for the distance of the migrated MSCs.

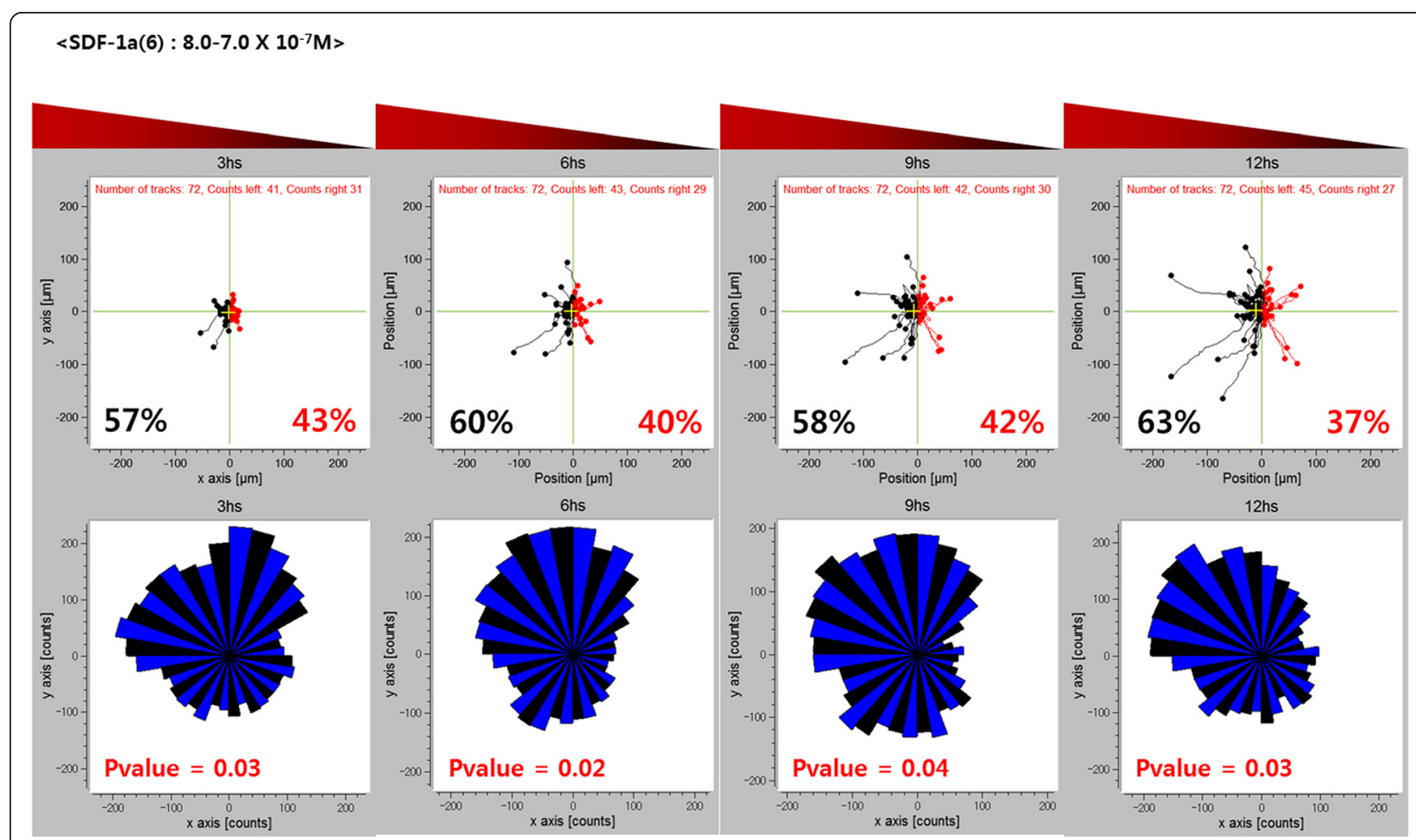

Fig. 6 Chemotatic response on a time scale of hours. The percent of hMSCs exhibiting movement towards and away from the SDF-1a are shown in black and red fonts, respectively. The bottom plots show the corresponding rose plots, where $\mathrm{n}$ is the number of individual cells tracked, and $p$ is the $p$-value calculated using the rayleigh test for vector data. Pvalue denote histograms with statistically significant asymmetry $(p<0.05)$ 
Distance analysis in the $\mathrm{X}$-direction $(\Delta \mathrm{X})$ was done with SPSS which presented the histograms of the possibility frequency with $\Delta \mathrm{X}(\mu \mathrm{m})(-30 \mu \mathrm{m}$ to $30 \mu \mathrm{m})$ (Fig. 5). Negative signals imply the migration of cells toward a direction to a higher concentration and positive signals toward a direction to a lower concentration. Moreover, tracking analysis of the migrated cells was done with the maximum concentrations of 8.0-7.0 $\times 10^{-7}$ and 8.0-7.0 $\times$ $10^{-8} \mathrm{M}$. The histogram in the case of SP $\left(8.0-7.0 \times 10^{-8}\right.$ M) showed a broader distribution than that of the others. This shows that the hMSCs at this concentration range were actively migrating compared to the other groups. In addition, the histograms are uniformly distributed which means the cells did not migrate asymmetrically through the channel. Based on the result, it seems that the migration of hMSCs exhibited a chemokinesis tendency rather than a chemotaxis one.

\section{The chemotactic response over time}

One of the key advantages of this study using a 3D microfluidic device is that we can conduct cell migration analysis over time intervals from the recording of individual cell movements. We obtained an angular histogram by tracking cell movement for a SDF- $1 \alpha$ concentration range of $8.0-7.0 \times 10^{-7} \mathrm{M}$ every $3 \mathrm{~h}$ for $12 \mathrm{~h}$ (Fig. 6). The cells migrated toward the direction of the high concentration (black pathways). The angular histogram shows an asymmetry shape at a certain time point which means that the cells showed a chemotactic migration in response to SDF-1 $1 \alpha$. This result importantly means that the chemotactic migration of hMSCs is also time-dependent which needs to be taken into consideration. Additionally, stable construction of long-term concentration gradients in microfluidic devices is essential for precise analyses of cell migration behaviors to determine if cells show chemokinesis or chemotaxis [25]. The data suggest that some factors at optimal concentrations show chemokinesis or chemotaxis in 3D hydrogelbased microfluidic devices. Many previous studies have reported on the hMSC migration behaviors induced by chemokines and growth factors in only a two dimensional (2D) culture [26-29].

\section{Conclusion}

In this study, we systematically investigated the chemotactic migration behaviors of hMSCs and their response to SDF-1 $1 \alpha$, IL- 8 and SP. SDF- $1 \alpha$ is one of the most fascinating chemoattractant candidates at certain time points among the factors tested in this study. We also found that each chemokine exhibited a different chemoattractant ability according to its concentration. Chemokines and growth factors in previous reports induce hMSCs migration towards a high concentration which is known as chemotaxis; however, we did not observed any noticeable chemotactic behaviors in MSCs. This discrepancy between our results and the results reported by other groups might be due to the system conditions (2D vs 3D).

\begin{abstract}
Abbreviations
BMSCs, bone marrow stromal cells; CXCR4, CXC chemokine receptor-4; ECM, extracellular matrix; hBM-MSCs, human bone marrow-derived mesenchymal stem cells; hMSCs, human mesenchymal stems cells; IL-8, interleukin-8; MSC, mesenchymal stems cell; NSC, neural stem cell; SDF-1a, stromal cell-derived factor-1 $a_{;}$SP, substance P; SPSS, statistical package for the social sciences
\end{abstract}

\section{Acknowledgement}

We specially thank Dr. Sewoon Han at Korea University for professional advice to prepare microfluidic devices

\section{Funding}

This work was supported by the research resettlement fund for the new faculty of Seoul National University, invitation program for distinguished scholar, and a grant from the Korea Institute of Science and technology (KIST, 2E24340).

\section{Availability of data and materials \\ Not applicable. \\ Further data shall not be shared because patent application is in progress.}

\section{Authors' contributions}

$\mathrm{KL}, \mathrm{CHA}$, DY and HJ developed the concept and designed experiments. DY, EL and MHP performed the whole process of experiments. SC provided the

3D microfluidic device. KL, DY and HK extensively contributed on the

manuscript preparation. All authors read and approved the final manuscript.

\section{Competing interests}

The authors declare that they have no competing interests.

\section{Consent for publication}

Not applicable.

\section{Ethics approval and consent to participate}

Not applicable.

\section{Author details}

${ }^{1}$ Center for Biomaterials, Korea Institute of Science and Technology, Seoul, Republic of Korea. ${ }^{2}$ Research Institute of Advanced Materials (RIAM), Department of Materials Science and Engineering, Seoul National University, Seoul, Republic of Korea. ${ }^{3}$ Program in Nanoscience and Technology, Graduate School of Convergence Science and Technology, Seoul National University, Seoul, Republic of Korea. ${ }^{4}$ School of Mechanical Engineering, Korea University, Seoul, Republic of Korea. ${ }^{5}$ Advanced Institutes of Convergence Technology, Gyeonggi-do, Republic of Korea.

Received: 26 May 2016 Accepted: 15 July 2016

Published online: 02 August 2016

\section{References}

1. Terranova VP, Deflorio R, Lyall R, Hic S, Friesel R, Maciag T. Human endothelial cells are chemotactic to endothelial cell growth factor and heparin. J Cell Biol. 1985:101:2330-4.

2. Li L, Jiang J. Regulatory factors of mesenchymal stem cell migration into injured tissues and their signal transduction mechanisms. Front Med. 2011;5: 33-9.

3. Chen Y, Xiang LX, Shao JZ, Pan RL, Wang YX, Dong XJ, et al. Recruitment of endogenous bone marrow mesenchymal stem cells towards injured liver. J Cell Mol Med. 2010;14:1494-508.

4. Wang Z, Wang Y, Wang Z, Gutkind JS, Wang Z, Wang F, et al. Engineered mesenchymal stem cells with enhanced tropism and paracrine secretion of cytokines and growth factors to treat traumatic brain injury. Stem Cells. 2015;33:456-67.

5. Sohni A, Verfaillie CM. Mesenchymal stem cells migration homing and tracking. Stem Cells Int. 2013;2013:130763. 
6. Chamberlain G, Fox J, Ashton B, Middleton J. Concise review: mesenchymal stem cells: their phenotype, differentiation capacity, immunological features, and potential for homing. Stem Cells. 2007;25:2739-49.

7. Ries C, Egea V, Karow M, Kolb H, Jochum M, Neth P. MMP-2, MT1-MMP, and TIMP-2 are essential for the invasive capacity of human mesenchymal stem cells: differential regulation by inflammatory cytokines. Blood. 2007;109: 4055-63.

8. Krause DS. Plasticity of marrow-derrived stem cells. Gene Ther. 2002;9:754-8.

9. Marquez-Curtis LA, Janowska-Wieczorek A. Enhancing the migration ability of mesenchymal stromal cells by targeting the SDF-1/CXCR4 axis. Biomed Res Int. 2013;2013:561098.

10. Cencioni C, Capogrossi MC, Napolitano M. The SDF-1/CXCR4 axis in stem cell preconditioning. Cardiovasc Res. 2012;94:400-7.

11. Breslin S, O'Driscoll L. Three-dimensional cell culture: the missing link in drug discovery. Drug Discov Today. 2013:18:240-9.

12. Tsui JH, Lee W, Pun SH, Kim J, Kim DH. Microfluidics-assisted in vitro drug screening and carrier production. Adv Drug Deliver Rev. 2013;65:1575-88.

13. Titmarsh DM, Chen HY, Glass NR, Cooper-White JJ. Concise review: microfluidic technology platforms: poised to accelerate development and translation of stem cell-derived therapies. Stem Cell Transl Med. 2014;3:81-90.

14. Young EWK, Beebe DJ. Fundamentals of microfluidic cell culture in controlled microenvironments. Chem Soc Rev. 2010;39:1036-48.

15. Xu H, Heilshorn SC. Microfluidic investigation of BDNF-enhanced neural stem cell chemotaxis in CXCL12 gradients. Small. 2013;9:585-95.

16. Han S, Yang K, Shin Y, Lee JS, Kamm RD, Chung S, et al. Three-dimensional extracellular matrix-mediated neural stem cell differentiation in a microfluidic device. Lab Chip. 2012;12:2305-8.

17. Boneschansker L, Yan J, Wong E, Briscoe DM, Irimia D. Microfluidic platform for the quantitative analysis of leukocyte migration signatures. Nat Commun. 2014;5:4787-98.

18. Kim BJ, Hannanta-Anan P, Chau M, Kim YS, Swartz MA, Wu M. Cooperative roles of SDF-1a and EGF gradients on tumor cell migration revealed by a robust 3D microfluidic model. PLoS One. 2013:8, e68422.

19. Keenan TM, Folch A. Biomolecular gradients in cell culture systems. Lab Chip. 2008:8:34-57.

20. Chung S, Sudo R, Mack PJ, Wan C-R, Vickerman V, Kamm RD. Cell migration into scaffolds under co-culture conditions in a microfluidic platform. Lab Chip. 2009;9:269-75.

21. Liu X, Duan B, Cheng Z, Jia X, Mao L, Fu H, et al. SDF-1/CXCR4 axis modulates bone marrow mesenchymal stem cell apoptosis, migration and cytokine secretion. Protein Cell. 2011;2:845-54.

22. Liang-kuan B, Nan Z, Cheng L, Fu-Ding L, Tian-Xin L, Xu-Jun X, et al. Kidney cancer cells secrete IL-8 to activate Akt and promote migration of mesenchymal stem cells. Urol Oncol. 2014;32:607-12.

23. Hong HS, Lee J, Lee E, Kwon YS, Lee E, Ahn W, et al. A new role of substance $P$ as an injury-inducible messenger for mobilization of $\mathrm{CD} 29(+)$ stromal-like cells. Nat Med. 2009;15:425-35.

24. Fujita S, Ohshima M, Iwata H. Time-lapse observation of cell alignment on nanogrooved patterns. J R Soc Interface. 2009;6:S269-77.

25. Ferreira MM, Dewi RE, Heilshorn SC. Microfluidic analysis of extracellular matrix-bFGF crosstalk on primary human myoblast chemoproliferation, chemokinesis, and chemotaxis. Integr Biol. 2015;7:569-79.

26. Wang L, Li Y, Chen X, Chen J, Gautam SC, Xu Y, et al. MCP-1, MIP-1, IL-8 and ischemic cerebral tissue enhance human bone marrow stromal cell migration in interface culture. Hematol. 2002;7:113-7.

27. Kalwitz G, Endres M, Neumann K, Skriner K, Ringe J, Sezer O, et al. Gene expression profile of adult human bone marrow-derived mesenchymal stem cells stimulated by the chemokine CXCL7. Int J Biochem Cell B. 2009; 41:649-58.

28. Ponte AL, Marais E, Gallay N, Langonne A, Delorme B, Herault O, et al. The in vitro migration capacity of human bone marrow mesenchymal stem cells: comparison of chemokine and growth factor chemotactic activities. Stem Cells. 2007;25:1737-45.

29. Cao J, Wang L, Du ZJ, Liu P, Zhang YB, Sui JF, et al. Recruitment of exogenous mesenchymal stem cells in mandibular distraction osteogenesis by the stromal cell-derived factor-1/chemokine receptor-4 pathway in rats. Brit J Oral Max Surg. 2013;51:937-41.

\section{Submit your next manuscript to BioMed Central and we will help you at every step:}

- We accept pre-submission inquiries

- Our selector tool helps you to find the most relevant journal

- We provide round the clock customer support

- Convenient online submission

- Thorough peer review

- Inclusion in PubMed and all major indexing services

- Maximum visibility for your research

Submit your manuscript at www.biomedcentral.com/submit

) Biomed Central 